\title{
Uji Ketertarikan Ngengat Spodoptera exigua Hubn. terhadap Perangkap Lampu Warna pada Pertanaman Bawang Merah (Allium ascalonicum L.)
}

\author{
Testing the Interest of Spodoptera exigua Hubn. in Colored Light Trap \\ in Onion (Allium ascalonicum L.) Planting
}

Yeny Mayang Sari ${ }^{1}$, Sigit Prastowo ${ }^{1}$ dan Nanang Tri Haryadi ${ }^{1}$

${ }^{1}$ Program Studi Agroteknologi, Fakultas Pertanian, Universitas Jember

Jl. Kalimantan 37, Kampus Tegal Boto, Jember 68121

*E-mail:prastowo_hpt@yahoo.com

Diterima 21 Desember 2016/Disetujui 14 Januari 2017

\begin{abstract}
Spodoptera exigua denotes an essential pest in the cultivation of onion and oftentimes causes great problems for onion farmers. The measure commonly taken to control the pest by the farmers is to use synthetic insecticide. Green appears interesting to spodoptera. This research was meant to reveal the impact of applying light trap on the existence of S. exigua. The research applied randomized group design with 6 treatments and 4 repetitions. The control treatment (with white-hued light), $(A)=$ chartreuse-colored trap, $(B)=$ lime-green-hued trap, $(C)=$ medium-sea-green-hued trap, $(D)=$ sea-green-hued trap, and $(E)=$ forest-green-hued trap. The data were analyzed using analysis of variance, which was consummated by Duncan Multiple Range Test (DMRT) at 5\% level. The research findings evinced that the highest number of caught moths, i.e. S. exigua, was 155 heads/plating period. The highest number of egg colonies was shown in treatment $E$ by 16 egg colonies. The highest number of larva was shown by treatment E, generating 653 larva. The highest damage extent due to S. exigua, reaching $15.69 \%$, was evident in treatment $E$, and the highest damage extent due to L. chinensis was evident in control, which reached a figure of $27.83 \%$. The highest crude weight and dry weight was discovered in treatment C, reaching 21.00 ton/ha and 15.83 ton/ha respectively.
\end{abstract}

Keywords: colored light trap,onion, S. Exigua

\section{ABSTRAK}

Hama Spodoptera exigua merupakan hama penting dalam pembudidayaan bawang merah dan sering menimbulkan permasalahan yang sangat merugikan petani bawang merah. Warna hijau merupakan warna yang menarik bagi ngengat spodoptera. Penelitian ini bertujuan untuk mengetahui pengaruh pemberian perangkap lampu warna terhadap keberadaan hama S. exigua. Penelitian ini menggunakan Rancangan Acak Kelompok dengan 6 perlakuan dan 4 ulangan. Perlakuan Kontrol (lampu warna putih), $(A)=$ perangkap warna chartreuse, $(B)=$ perangkap warna lime green,$(C)=$ perangkap warna medium sea green, $(D)=$ perangkap warna sea green, $(E)=$ perangkap warna forest green. Analisis data menggunakan analisis ragam yang dilanjutkan dengan Dancan Multiple Range Test (DMRT) $5 \%$. Hasil penelitian menunjukkan bahwa jumlah tangkapan ngengat S. exigua terbanyak adalah pada Kontrol dengn jumlah tangkapan 155 ekor ngengat/periode tanam. Jumlah koloni telur terbanyak ditunjukkan pada perlakuan E yaitu dengan jumlah 16 koloni telur,. Jumlah larva terbanyak ditunjukkan pada perlakuan E dengan jumah larva 653 ekor larva. Tingkat kerusakan akibat seranggan S. exigua tertinggi ditunjukkan perlakuan E dengan tingkat kerusakan 15,69\% kerusakan dan kerusakan tertinggi akibat L. chinensis ditunjukkan pada kontrol dengan kerusakan 27,38\% kerusakan. Berat basah dan berat kering tertinggi ditunjukkan pada perlakuan C dengan jumlah berat basah 21.00 ton/ha dan berat kering 15.83 ton/ha.

Kata Kunci: Bawang Merah, S. exigua, perangkap lampu warna.

\section{PENDAHULUAN}

Produksi bawang merah sejak tahun 2000-2012 dengan laju produksi rata-rata pertahun adalah sebesar 2.07 \%/tahun, pada akhir 2012 produksi bawang merah mencapai angka sekitar 960 ribu ton, sedangkan pada tahun 2015 ini produksi bawang merah diperkirakan sebesar 963.4 ribu ton (Rusono et al., 2013). Namun dalam pembudidaan bawang merah menemui banyak kendala, di antaranya adalah serangan Organisme

Pengganggu Tumbuhan (OPT) (Udiarto et al., 2005). Hama yang sering menyerang pada budidaya bawang merah 
adalah Spodoptera exigua Hubn, Thrips tabaci Lind dan Agrotis ipsilon Hufn (Rukmana, 1994). Serangan hama S. exigua pada budidaya pertanaman bawang merah menjadi sangat penting karena dapat menurunkan kualitas dan kuantitas produksi sehingga petani bawang merah merugi (Putrasamedja et al., 2012).

Keberadaan hama $S$. exigua menjadi permasalahan yang sangat merugikan petani bawang merah, serangga ini dikenal sebagai hama yang polifag (Suheriyanto et al., 2001). Selain bawang merah, tanaman inang lain dari $S$. exigua adalah tanaman cabai, kubis, tomat, bayam, kapas, jagung, tembakau, kedelai dan sebagainya (Moekasan, 1998). Hama ini juga disebut sebagai ulat grayak karena seranggannya mendadak dan dalam jumlah yang banyak dapat mengakibatkan kerugian total, dimana hasil produksi yang maksimal adalah 20 ton/ha (Febrianasari et al., 2014).

Penggunaan insektisida sintetik untuk pengendalian $S$. exigua sering menimbulkan masalah diantaranya adalah pembengkakan biaya perawatan karena pembelian insektisida sintetik yang mahal (Moekasan dan Murtiningsih, 2010). Disamping harga insektisida sintetik yang mahal dan hama yang semakin resisten dengan insektisida yang digunakan, maka petani lebih memilih pengendalian secara mekanik contohnya adalah dengan menggunakan jaring (sweeping) (Darmawan et al., 2013). Selain menggunakan jaring, penggunaan perangkap lampu (light trap) banyak digunakan oleh para petani di daerah Kabupaten Nganjuk untuk menekan terjadinya seranggan $S$. exigua sehingga penggunaan insektisida dapat berkurang (Saikhu, 2015). Hasil yang diperoleh dengan menggunakan light trap sangatlah terlihat karena dapat menekan tingkat kerusakan. Penggunaan perangkap merupakan salah satu alternatif yang dapat dilakukan untuk mencegah seranggan S. exigua agar tanaman bawang merah dapat terselamatkan.

Hasil pengamatan di daerah Kabupaten Nganjuk menunjukkan bahwa perangkap warna yang terbuat dari botol-botol bekas berwarna ini baru-baru ini diterapkan oleh petani. Hasil penelitian Yudhistira et al. (2014), menunjukkan bahwa serangga dengan ordo Lepidoptera spesies $S$. litura merupakan serangga yang tertarik dengan warna hijau. Serangga sangat tertarik pada benda yang dapat memantulkan cahaya dengan kisaran panjang gelombang antara 245-600 nm (Sunarno, 2011). Warna yang berada dikisaran kisaran panjang gelombang 254-650 nm adalah warna ungu (380-450 nm), biru (450-490 nm), hijau (490$560 \mathrm{~nm}$ ), dan kuning (560-590) (Sugito et al., 2005).

Penelitian ini bertujuan untuk mengetahui pengaruh pemberian perangkap lampu warna terhadap keberadaan hama S. exigua.

\section{BAHAN DAN METODE}

\section{Penyediaan bahan tanam}

Bibit bawang merah varietas Thailand diperoleh dari petani lokal. Bibit varietas Thailand merupakan varietas bawang merah yang banyak ditanam di daerah Nganjuk. Varietas ini cocok ditanam pada musim hujan dan kemarau. Bibit varietas Thailand yang siap tanam biasanya berkisar 60 hari setelah panen. Keunggulan varietas Thailand adalah bobotnya lebih berat dibandingkan dengan varietas lain, daya simpan lama, dan daya tumbuh varietas ini lebih cepat (Putrasamedja dan Suwandi, 1996).

\section{Pembuatan dan Pemasangan Perangkap}

Perangkap dapat dibuat dengan menggunakan botol bekas, cat warna dan bola lampu, dengan memasang bola lampu kedalam botol bekas dan kemudian memberi loyang berisi air sabun kedalamnya. Perangkap yang telah dibuat selanjutnya dipasang pada ajir setinggi $60 \mathrm{~cm}$. Ketinggian perangkap dipasang setinggi $60 \mathrm{~cm}$ karena ketinggian terbang ngengat $S$. exigua adalah sekitar 1.5 meter (Nurhayati, 2011). Lampu dinyalakan pada saat menjelang petang, yaitu sekitar pukul 17.30 WIB hingga pukul 19.00 WIB (Rachman 2005). Sumber lampu diperoleh dari perumahan warga dengan jarak perumahan dan petak percobaan adalah 200 meter.

Variabel pengamatan Jumlah Tangkapan Ngengat $S$. exigua pada Perangkap Lampu Warna

Pengamatan jumlah imago yang tertangkap dapat dilakukan setiap hari sejak tiga hari setelah tanam hingga tanaman siap panen. Pengamatan dilakukan dengan cara melihat dan menghitung jumlah ngengat $S$. exigua dengan interfal pengamatan 2 hari sekali, yang kemudian akan diamati pada malam hari yaitu pada pukul 19.00 WIB. Berdasarkan hasil yang diperoleh, maka nantinya dapat diketahui tingkat serangan dan kerusakan yang ditimbulkan akibat serangan $S$. exigua.

\section{Jumlah Koloni Telur, Larva dan Jarak Peletakan Telur dengan Perangkap Lampu Warna yang Terdapat pada Petak Percobaan}

Pengamatan dilakukan secara langsung pada petak percobaan. Pengamatan dilakukan setelah tanaman berumur 7 HST dengan interval pengamatan 3 hari, pengamatan dilakukan pada seluruh jumlah tanaman dalam setiap ulangan hingga tanaman siap panen (Rauf, 1999).

Keterangan :

$$
\mathrm{P}(\mathrm{I})=(\mathrm{A} / \mathrm{B}) \times 100 \%
$$

$\mathrm{P}(\mathrm{I})=$ Intensitas serangan/kerusakan tanaman

$\mathrm{A}=$ Jumlah tanaman yang rusak dari keseluruhan unit sampel yang diamati

$\mathrm{B}=$ Jumlah keseluruhan tanaman yang diamati

\section{Analisis data}

Hasil penelitian dianalisis dengan analisis sidik ragam (ANOVA), jika analisis menunjukkan hasil berbeda nyata maka dilanjutkan dengan uji Duncan Multiple Range Test (DMRT) dengan taraf 5\%.

\section{HASIL DAN PEMBAHASAN}




\section{Jumlah Tangkapan Ngengat S. exigua pada Perangkap Lampu Warna, Jumlah Koloni Telur, Jumlah Larva dan Jarak Peletakan Telur dari Perangkap Lampu Warna}

Berdasarkan hasil anova jumlah ngengat, jumlah koloni telur, jumlah larva dan jarak peletakan telur, menunjukkan bahwa perlakuan C (perangkap warna medium sea green) merupakan perlakuan terbaik dibandingkan dengan warna lainnya.

Hasil pengamatan jumlah ngengat, jumlah koloni telur, jumlah larva dan jarak peletakan telur dapat dapat dilihat pada Tabel 4.2. Ngengat $S$. exigua terbanyak pada perlakuan C (medium sea green) dengan jumlah 69 ekor/periode tanam dibandingkan dengan perlakuan warna lainya, akan tetapi kemampuan menangkap ngengat $S$. exigua dengan perlakuan warna hijau lebih rendah dibandingkan kontrol dengan jumlah tangkapan 155 ekor/periode tanam bawang merah. Jumlah koloni telur ngengat S. exigua terbanyak adalah pada perlakuan E (forest green) dengan jumlah 16 koloni telur, sedangkan jumlah paling sedikit yaitu pada perlakuan A (chartreuse) dengan jumlah 7 koloni telur. Jumlah koloni telur berbanding lurus dengan jumlah larva yang ditemukan pada setiap perlakuan. Jumlah larva $S$. exigua terbanyak adalah pada perlakuan E (forest green) dengan jumlah 653 larva dan larva S. exigua paling sedikit adalah pada perlakuan A (chartreuse) dengan jumlah 389 larva. Sedangkan jarak perangkap dengan peletakan telur yang ditemukan menunjukkan hasil yang tidak berbeda nyata. Pada pengamatan jumlah, keberadaan ngengat $S$. exigua terjadi pada saat fase vegetatif dan fase generatif.

Hasil penelitian menunjukkan bahwa cahaya warna hijau kurang menarik bagi ngengat $S$. exigua dibandingkan dengan cahaya warna putih. Hal ini ditunjukkan pada Tabel 2 yang menunjukkan bahwa ngengat $S$. exigua kurang tertarik dengan cahaya warna hijau dibandingkan dengan cahaya warna putih. Kekuatan cahaya lampu berpengaruh terhadap jumlah ngengat yang datang, lampu yang berkekuatan lebih besar akan menarik kedatangan ngengat lebih banyak (Yunus et al., 2011). Warna hijau tidak menarik ngengat $S$. exigua sebagai perangkap akan tetapi penggunaan cahaya warna hijau justru menarik ngengat untuk meletakan telurnya, hal ini ditunjukkan pada tabel 4.1. Ngengat $S$. exigua akan meletakkan telurnya jauh dari sumber cahaya (Rachman, 2005). Penggunaan perangkap cahaya warna hijau dapat menekan intensitas kerusakan akibat $S$. ехigua akan tetapi tidak dapat menekan intensitas kerusakan akibat $L$. chinensis. Sehingga serangan akibat $S$. exigua tidak berpengaruh terhadap produksi.

Pada penelitian Widyastuti (2009), ngengat Spodoptera lebih tertarik dengan warna hijau dibandingkan dengan warna lainnya (putih, biru dan kuning). Warna hijau yang dapat menarik ngengat Spodoptera paling tinggi adalah warna Brouge Green (Yudhistira et al., 2014). Serangga mempunyai dua tipe pigmen penglihatan, yaitu pigmen yang dapat menyerap warna biru dan sinar ultraviolet serta pigmen yang dapat menyerap warna hijau dan kuning (Sunarno, 2011). Serangga akan lebih tertarik pada spektrum berwarna hijau-kuning (400-600 nm) yang merupakan kisaran panjang gelombang dari inangnya (Metcalf dan Metcalf, 1992).

Hasil penelitian menunjukkan bahwa perangkap lampu warna hijau yang paling disukai ngengat $S$. exigua adalah perlakuan $\mathrm{C}$ (medium sea green) dibandingkan dengan perlakuan lainnya. Akan tetapi kemampuan menangkap ngengat $S$. exigua pada perangkap lampu warna hijau lebih rendah dibandingkan dengan kontrol. Hal ini diduga karena cahaya lampu pada kontrol lebih terang dibandingkan dengan perlakuan lainnya. Menurut Rachman (2005), cahaya lampu warna putih akan lebih menarik bagi ngengat S. exigua dibandingkan dengan cahaya lampu warna kuning. Kisaran panjang gelombang yang dihasilkan oleh lampu neon 10 watt adalah berkisar antara $379.2-640.9 \mathrm{~nm}$ (Deomedes et al., 2007).Warna cahaya yang berbeda akan memancarkan perbedaan panjang gelombang yang berbeda pula (Syahri et al., 2011). Sementara itu semakin jauh atau redupnya cahaya, kemungkinan semakin kecil serangga untuk mendekat (Akmal et al., 2007).

Tabel 1 Jumlah Ngengat S. exigua yang Tertangkap pada Perangkap Lampu Warna, Jumlah Koloni Telur, Larva, dan Jarak Peletakan Telur S. exigua pada Tanaman Bawang Merah

\begin{tabular}{|c|c|c|c|c|c|c|}
\hline \multirow{2}{*}{$\begin{array}{c}\text { Perlakuan } \\
\text { Kontrol }\end{array}$} & \multirow{2}{*}{$\begin{array}{r}\text { Jumlah } \\
155\end{array}$} & \multirow{2}{*}{ Ngengat } & \multicolumn{2}{|c|}{$\begin{array}{l}\text { Jumlah Koloni } \\
\text { Telur }\end{array}$} & $\begin{array}{c}\text { Jumlah Larva } \\
\text { (ekor/periode tanam) }\end{array}$ & \multirow{2}{*}{$\begin{array}{l}\text { Jarak }(\mathrm{cm})(*) \\
167.26\end{array}$} \\
\hline & & & 7 & $\mathrm{c}$ & $389 \mathrm{c}$ & \\
\hline A & 16 & $\mathrm{~d}$ & 12 & $\mathrm{ab}$ & $547 \quad \mathrm{~b}$ & 174.96 \\
\hline B & 31 & $\mathrm{~cd}$ & 10 & $\mathrm{~b}$ & $545 \quad \mathrm{~b}$ & 179.97 \\
\hline $\mathrm{C}$ & 69 & $\mathrm{~b}$ & 9 & $\mathrm{~b}$ & $490 \quad b c$ & 166.19 \\
\hline $\mathrm{D}$ & 52 & $\mathrm{bc}$ & 10 & $\mathrm{~b}$ & $526 \quad \mathrm{~b}$ & 161.37 \\
\hline E & 5 & $\mathrm{e}$ & 16 & $\mathrm{a}$ & 653 a & 146.62 \\
\hline Rerata & 55 & & 10,67 & & 525 & 166.06 \\
\hline
\end{tabular}

Keterangan: Angka yang diikuti huruf kecil yang tidak sama pada kolom yang sama menunjukkan hasil berbeda nyata pada uji Duncan dengan taraf 5\%. (*jarak perangkap lampu warna dengan koloni telur yang ditemukan). 
Tabel 2 Persentase Tanaman Terserang S. exigua dan L. chinensis, Berat Basah dan Berat Kering Tanaman Bawang Merah

\begin{tabular}{|c|c|c|c|c|c|c|c|c|}
\hline \multirow{3}{*}{$\begin{array}{c}\text { Perlakuan } \\
\text { Kontrol }\end{array}$} & \multicolumn{4}{|c|}{$\begin{array}{c}\text { Tanaman Terserang (\% } \\
\text { Kerusakan) }\end{array}$} & \multirow{2}{*}{\multicolumn{2}{|c|}{$\begin{array}{l}\text { Berat Basah } \\
\text { (ton/ha) }\end{array}$}} & \multirow{2}{*}{\multicolumn{2}{|c|}{ Berat Kering (ton/ha) }} \\
\hline & \multicolumn{2}{|c|}{ S. ехіgиа } & \multicolumn{2}{|c|}{ L. chinensis } & & & & \\
\hline & 9,69 & $\mathrm{~b}$ & 27,38 & $\mathrm{a}$ & 13,67 & $\mathrm{~b}$ & 10,17 & $\mathrm{~b}$ \\
\hline A & 13,63 & $\mathrm{a}$ & 14,25 & $\mathrm{~b}$ & 19,00 & $\mathrm{a}$ & 14,17 & $\mathrm{a}$ \\
\hline B & 13,06 & $a b$ & 14,00 & $\mathrm{~b}$ & 19,33 & $\mathrm{a}$ & 14,50 & $\mathrm{a}$ \\
\hline $\mathrm{C}$ & 10,06 & $\mathrm{~b}$ & 8,50 & $\mathrm{c}$ & 21,00 & $\mathrm{a}$ & 15,83 & $\mathrm{a}$ \\
\hline D & 12,94 & $a b$ & 12,94 & $\mathrm{bc}$ & 19,83 & $\mathrm{a}$ & 14,83 & $\mathrm{a}$ \\
\hline E & 15,69 & $\mathrm{a}$ & 17,75 & $\mathrm{~b}$ & 16,83 & $a b$ & 12,67 & $\mathrm{ab}$ \\
\hline Rerata & 12,51 & & 15,80 & & 109,6 & & 83,16 & \\
\hline
\end{tabular}

Keterangan: Angka yang diikuti huruf kecil yang tidak sama pada kolom yang sama menunjukkan hasil berbeda nyata pada uji Duncan dengan taraf $5 \%$.

\section{PersentaseTanaman Terserang $S$. exigua dan $L$. chinensis, Berat Basah dan Berat Kering Tanaman Bawang Merah}

Berdasarkan hasil anova tanaman terserang S. exigua dan L. chinensis, berat basah dan berat kering tanaman bahwa berat basah dan berat kering tanaman bawang merah tidak dipengaruhi oleh serangan $S$. exigua

Persentase tanaman terserang $S$. exigua paling tinggi ditunjukkan pada perlakuan E (forest green) dengan nilai $15.69 \%$ kerusakan, sedangkan persentase tanaman terserang S. exigua terendah ditunjukkan pada kontrol dengan nilai $9.69 \%$. Sedangkan tanaman terserang $L$. chinensis paling tinggi ditunjukkan pada kontrol dengan nilai $25.75 \%$ kerusakan dan jumlah paling rendah ditunjukkan pada perlakuan C (medium sea green) dengan nilai $8.31 \%$ kerusakan. Jumlah berat basah dan berat kering tertinggi didapat pada perlakuan C (medium sea green) dengan jumlah berat basah 21 ton/ha dan berat kering 15.83 ton/ha. Sementara itu jumlah berat basah dan berat kering terendah didapat pada kontrol (warna putih), dengan jumlah berat basah 13.67 ton/ha dan berat kering 10.17 ton/ha. Penurunan berat kering bawang merah turun sekitar $25-30 \%$ dari berat basah (Rukmana, 1994).

Persentase tanaman terserang $S$. exigua paling tinggi ditunjukkan pada perlakuan E (forest green) dengan nilai $15.69 \%$ kerusakan, sedangkan persentase tanaman terserang S. exigua terendah ditunjukkan pada kontrol dengan nilai $9.69 \%$. Hal ini diduga karena ngengat S. exigua akan meletakkan telurnya pada tempat yang lebih gelap dibandingkan dengan tempat yang lebih terang. Dalam hal ini maka dapat diketahui bahwa semakin banyak serangga yang tertangkap pada perangkap lampu warna maka kesempatan serangga dalam meletakkan telurnya rendah. Tertangkapnya ngengat $S$. exigua akan berpengaruh terhadap aktifitas jantan dan betina untuk bertemu sehingga tingkat serangan oleh $S$. exigua pada pertanaman bawang merah juga akan terpengaruh. Sedangkan tanaman terserang $L$. chinensis paling tinggi ditunjukkan pada kontrol dengan nilai $25.75 \%$ kerusakan dan jumlah paling rendah ditunjukkan pada perlakuan C (medium sea green) dengan nilai $8.31 \%$ kerusakan. Keberadaan $S$. exigua tidak berpengaruh terhadap produksi bawang merah. Akan tetapi produksi bawang merah lebih besar dipengaruhi oleh keberadaan hama lain yaitu L. chinensis. Selain itu prosuksi bawang merah berbeda antar perlakuan juga diduga karena beberapa faktor diantaranya adalah varietas yang digunakan, lahan yang digunakan, pupuk tidak efisien serta pengaruh penggunaan pestisida (Listianawati, 2014).

Keberadaan ngengat $S$. exigua ditemukan pada fase vegetatif dan fase generatif. Ditemukannya ngengat $S$. exigua pada fase vegetatif diduga karena tanaman sebelumnya adalah tanaman bawang merah sehingga tidak mengalami rotasi tanam. Akan tetapi keberadaan ngengat $S$. exigua pada fase vegetatif tidak sebanyak pada fase generatif, hal ini diduga karena ngengat $S$. exigua terisolasi dengan tanaman sekitar. Seranggan hama $S$. exigua dapat dijumpai hampir di setiap fase pertumbuhan tanaman bawang merah (Prasetyo, 2016). Di sekitar tanaman bawang merah telah ditanami padi yang sudah berumur 50 hari. Serangan hama dapat terhindarkan apabila tanaman terisolasi dengan tanaman lain disekitarnya (Mc Ewen, 1997).

Menurut Oka (1998), hama dapat lebih mudah menemukan tanaman inangnya pada area pertanaman monokultur, sehingga dalam sistem monokultur hama yang akan ditemukan akan lebih tinggi dibandingkan dengan pola tanam polikultur. Hal demikian terjadi pada petak percobaan yang telah dilakukan, dimana tanaman sekitar petak percobaan tidak hanya tanaman bawang merah saja. Tanaman padi dan tanaman jagung yang berada di sekitar tanaman bawang merah akan menambah keragaman ekosistem dibandingkan apabila pada area tersebut hanya ditanami tanaman bawang merah saja. Ekosistem yang beragam dapat menekan keberadaan hama utama pada pertanaman bawang merah. Menurut Oka (1998), pola tanam seperti padi-padi-palawija dapat menekan keberadaan organisme pengganggu tanaman. Rotasi tanam dapat pula berpengaruh terhadap hasil tangkapan lampu perangkap. Rotasi tanam yang dilakukan petani bawang merah akan dapat menekan perkembangbiakan S. exigua (Pracaya, 1999). Pada fase vegetatif saat tanaman berumur 3 hst 
hingga 19 hst masih terjadi serangan S. exigua. Diduga hal ini karena tanaman sebelumnya yang merupakan tanaman bawang merah akan berpengaruh dengan jumlah tangkapan selanjutnya.

Keberadaan ngengat $S$. exigua sendiri juga dipengaruhi dengan kondisi alami disekitar lahan. Suhu, arah angin, hujan dan cahaya bulan akan mempengaruhi aktivitas terbang ngengat (Mc Ewen, 1997). Ngengat $S$. exigua merupakan serangga berdarah dingin, sehingga bila suhu lingkungan menurun maka akan berpengaruh terhadap aktivitas. Semakin malam suhu udara semakin dingin sehingga aktivitas terbang ngengat $S$. exigua juga akan rendah. Sementara jika terjadi hujan maka juga akan mempengaruhi aktivitas terbang ngengat, ngengat tidak dapat terbang pada kondisi hujan. Sementara itu cahaya bulan juga akan berpengaruh terhadap penglihatan serangga ini. Ngengat $S$. exigua cenderung lebih suka mendekati lampu perangkap putih dibandingkan dengan lampu perangkap yang lain. Hal ini diduga karena cahaya yang dihasilkan oleh lampu putih lebih menarik bagi mata serangga $S$. exigua.Kemungkinan dari cahaya lengkap tersebut maka lebih menarik bagi ngengat $S$. exigua.

Pengaruh cahaya terhadap perilaku serangga berbeda antara serangga yang aktif siang hari dengan yang aktif pada malam hari. Organ penglihatan serangga sangatlah dipengaruhi oleh keberadaan intensitas cahaya disekitarnya, sehingga intensitas cahaya akan mempengaruhi keberadaan serangga dialam (Aditama dan Kurniawan, 2013). Pada malam hari keaktifan serangga dirangsang oleh keadaan intensitas maupun panjang gelombang cahaya disekitarnya (Susniahti et al., 2005). Keberadaan hama L. chinensis pada petak percobaan diduga karena memiliki kemampuan untuk beradaptasi yang tinggi, sehingga perilakunya mudah terpengaruh oleh kondisi fisik lingkungan (Alim dan Ramza., 2009). Serangga L. chinensis merupakan serangga yang aktif pada pagi hari dan sore hari (krepuskular) (Kuatsar et al., 2015). Sehingga dengan keberadaan lampu yang menyala selama pengamatan, secara langsung akan mempengaruhi aktivitas terbang serangga L. chinensis. Dalam penelitian Rasid (2012), serangga dengan ordo Diptera lebih tertarik pada warna kuning dan putih daripada dengan warna yang lainnya. Jumlah berat basah dan berat kering tertinggi didapat pada perlakuan $\mathrm{C}$ dengan jumlah berat basah 21 ton/ha dan berat kering 15,83 ton/ha. Sementara itu jumlah berat basah dan berat kering terendah didapat pada kontrol, dengan jumlah berat basah 13.67 ton/ha dan berat kering 10.17 ton/ha. Penurunan berat kering bawang merah turun sekitar $25-30 \%$ dari berat basah (Rukmana, 1994).

\section{KESIMPULAN}

Berdasarkan hasil dan pembahasan dari penelitian yang telah dilakuakn didapat kesimpulan bahwa perangkap lampu warna hijau dengan perlakuan C (medium sea green) lebih menarik bagi ngengat $S$. exigua dibandingkan dengan perlakuan lain,akan tetapi juka dibandingkan dengan warna putih pada kontrol, perlakuan kontrol lebih menarik ngengat S. exigua.

\section{DAFTAR PUSTAKA}

Aditama. R.C., dan N. Kurniawan. 2013. Struktur Komunitas Serangga Nocturnal Areal Pertanaman Padi Organik pada MusimPenghujan di Kecamatan Lawang, Kabupaten Malang. J. Biotropika, 1(4): 186190.

Akmal, I., G. Savitri., dan N. Arimbi. 2007. Simple Garden. Jakarta: Gramedia Pustaka Utama.

Alim, E.S., dan H. Ramza. 2009. Piranti Perangkap Serangga (Hama) dengan Intensitas Cahaya. Hasil Penelitian Hibah Bersaing: DP2M DIKTI.Darmawan E.W.B., T. Himawan., H. Tarno., dan H Sutrisno. 2013. Identifikasi beberapa jenis ngengat jantan genus Arctornis (Lepidoptera: Noctuoidae) Di Indonesia Berdasarkan Karakter Morfologi dan Genetalia. HPT, 1(4): 42-50.

Darmawan, E.W.B., T. Himawan., H. Tarno., dan H Sutrisno. 2013. Identifikasi beberapa jenis ngengat jantan genus Arctornis (Lepidoptera: Noctuoidae) Di Indonesia Berdasarkan Karakter Morfologi dan Genetalia. HPT, (4): 42-50.

Deomedes, Y.I. Piyoh., Y.A. Talangas., D.N. Sudjito., dan F.S. Rondonuwu. 2007. Pemanfaatan Kamera Digital untuk Mengukur Panjang Gelombang Spektrum Neon. Prosiding Pertemuan Ilmiah (25) : 69-71.

Febrianasari, R., H. Tarno., dan A. Afandhi. 2014. Efektifitas klorantraniliprol dan flubendianid pada ulat bawang merah (Spodoptera exigua Hubner) (Lepidoptera : Noctuidae). J. HPT, 2(4) : 103-109.

Kuatsar. M.A., Riyanto, dan S. Huzaifah. 2015. Keragaman Jenis Serangga Nokturnal di Kebun Botani Kampus FKIP Universitas Sriwijaya Indralaya dan Sumbangannya Pembelajaran Biologi di SMA. J. Pembelajaran Biologi, 2(2) : 124-136.

Listianawati, N.N. 2014. Analisis Faktor-Faktor yang Mempengaruhi Produksi Bawang Merah di Desa Kupu Kecamatan Wanasari Kabupaten Brebes. Jakarta: Universitas Islam Negeri Syarif Hidayatullah

Mc Ewen, P. 1997. Sampling Handling and Rearing Insects. Pp. 5-20. Dalam D.R. Dent dan M.P Walton (eds). Methods in Ecological and Agricultural Entomology. CAB International, Wallingford.

Metcalf R.L. dan E.R. Metcalf. 1992. Plant Kairomones in Insect Ecology and Control. Canada. J. Biochem, 24(12): 1997.

Moekasan, T.K. 1998. Insektisida Mikroba Untuk Mengendalikan Hama Ulat Bawang, Spodoptera exigua. Bandung: Balai Penelitian Tanaman Sayuran. 
Moekasan, T.K. dan R. Murtingsih. 2010. Pengaruh Campuran Insektisida terhadap Ulat Bawang Spodoptera exigua Hubn. J. Hortikultura, 20(1): 6779.

Nurhayati H. 2011. Analisa Hama Ulat Bawang (Spodoptera exigua) Pada Tanaman Bawang Merah (Allium cepa). Bogor: Institut Pertanian Bogor.

Oka, I. N. 1998. Pengendalian Hama Terpadu. Yogyakarta: Gadjah Mada University Press.

Pracaya. 1999. Hama dan Penyakit Tanaman. Bogor; Penebar Swadaya.

Prasetyo, G.W.A. 2016. Pengendalian Hama Ulat Bawang (Spodoptera exigua) pada Tanaman Bawang Merah (Allium cepa). Universitas Jendral Soedirman.

Putrasamedja, S. dan Suwandi. 1996. Bawang Merah di Indonesia. Bandung: Balai Penelitian Tanaman Sayuran.

Putrasamedja, S., W. Setiawati, L. Lukman, dan A. Hasyim. 2012. Penampilan beberapa klon bawang merah dan hubungannya dengan intensitas serangan organisme pengganggu tumbuhan J. Hort, 22(4) : 349-359.

Rachman, A. 2005. Hubungan perangkap lampu (Light Trap) dengan aktivitas ngengat Spodoptera exigua Hubn. Pada tanaman bawang merah (Alliumascalonicum L). Jember : Universitas Jember.

Rasid, M.R. 2012. Laporan Praktikum Ilmu Hama Tumbuhan Dasar Percobaan Uji Preferensi Warna. Institut Peranaian Bogor.

Rauf, A. 1999. Dinamika Populasi Spodoptera exigua (Hubner) (Lepidoptera : Noctuidae) pada Pertanaman Bawang Merah di Dataran Rendah. J. Buletin Hama dan Penyakit Tumbuhan, 11(2) : 39-47.

Rukmana, R. 1994. Bawang Merah (budidaya dan pengelolaan pascapanen). Yogyakarta : Kanisius.

Rusono, N., A. Suanri., A. Candradijaya., A. Muharam., I. Martino., Tejaningsih., P.U. Hadi., S.H. Susilowati., dan M. Maulana. 2013. Rencana Pengembangan Pembangunan Jangka Menengah Nasional (RPJMN) Bidang Pangan dan Pertanian 2015-2019. Jakarta : Direktorat Pangan dan Pertanian.
Saikhu, A. 2015. Pengendalian Hama Terpadu dengan Lampu LED (Light Trap). http://cybex.ipb. ac.id/index.Php/ artikel /detail/Berita/368 . Diakses pada 20-12-2015.

Sugito. H., S.B. Wahyu, K. S. Firdausi, dan S. Mahmudah. 2005. Pengukuran Panjang Gelombang Sumber Cahaya Berdasarkan Pola Interferensi Celah Banyak. J. Berkala Fisika, 8(2): 37-44.

Suheriyanto D. 2008. Ekologi Serangga. Malang: UIN Malang Press Sunarno, 2005.

Suheriyanto, D., L. Agustina, dan G. Mudjiono. 2001. Kajian Komunitas Fauna pada Pertanaman Bawang merah dengan dan Tanpa Aplikasi Pestisida. Malang: Unibraw.

Sunarno. 2011. Ketertarikan Serangga Hama Lalat Buah Terhadap Berbagai Papan Perangkap Berwarna Sebagai Salah Satu Teknik Pengendalian. Agroforestri, 5 (2): 129-134.

Susniahti, N., Sumeno, dan Sudarjat. 2005. Bahan Ajar Ilmu Hama Tumbuhan. Bandung: Universitas Padjajaran.

Syahri, T. Thamrin., dan Y. Hutapea. 2011. Tinjauan Perbaikan Teknologi Pascapanen Padi Untuk Menekan Serangan Serangga Hama Gudang. Universitas Padjajaran: Seminar Nasional Perhimpunan Entomologi Indonesia.

Udiarto. B.K., W. Setiawati., dan. E. Suryaningsih. 2005. Pengenalan Hama dan Penyakit pada Tanaman Bawang Merah dan Pengendaliannya. Bandung: Balai Penelitian Tanaman Sayuran.

Widyastuti Y.U. 2009. Ketertarikan Spodoptera litura F. Terhadap Papan Perangkap Berwarna di Area Tanaman Melon (Cucumis melo L.) di Desa Bayuran Bantul. Yogyakarta: Universitas Atma Jaya.

Yudhistira, A.K.S., W.N. Jati., dan Y. Aida. 2014. Ketertarikan Ngengat Spodoptera litura Fabricus Terhadap Warna Hijau Di Are Tanaman Melon. Yogyakarta: Universitas Atma Jaya.

Yunus, M., E. Martono., Awijonarko, dan R.C.H. Soesilohadi. 2011. Aktifitas Ngengat Scirpophaga Incertulas di Wilayah Kabupaten Klaten. $J$. Perlindungan Tanaman Indonesia, 17(1): 18-25.. 